have an increased incidence of tissue antibodies and abnormal immunoglobulin levels, ${ }^{4}$ and the presence of a genetic factor is also suggested by the finding of an increased frequency of the histocompatibility antigens $\mathrm{HL}-\mathrm{Al}$ and $\mathrm{HL}-\mathrm{A} 8$ in active chronic hepatitis as compared with a normal control population. ${ }^{5}$

The finding of hepatitis B antigen (HBAg) in the serum of some patients with active chronic hepatitis $-18 \%$ in a recent study $^{6}$ from Britain-has raised the possibility that not all cases have the same immunopathology. Clinical and serological differences between $\mathrm{HBAg}$-positive and HBAg-negative cases of this disease have been emphasized in a number of reports. Those carrying the antigen have been described as both younger ${ }^{7}$ and older. ${ }^{8}$ Gammaglobulin levels were said to be lower, ${ }^{89}$ tissue antibodies absent from the serum, ${ }^{8-10}$ biochemical abnormalities less severe, and prognosis better. ${ }^{8}$ Such differences, however, were not confirmed in the most recent study by Reed et al., ${ }^{6}$ who found that apart from an increased frequency of the antigen in males (up to $36 \%$ ) and in those born outside Britain the two groups seemed identical. Recognition of a male preponderance in the antigen-positive group is important. If it is ignored in statistical analyses of serum autoantibody patterns misleading results will be obtained, because the frequency of these autoantibodies is lower in males than in females. Reed and his colleagues ${ }^{6}$ found a lower frequency of antinuclear antibodies in the HBAgpositive than in the antigen-negative cases, but this was simply related to the greater number of males in the former group.

Another possibly distinct subgroup are those patients in whom the LE cell test is positive, who constitute some $15 \%$ in most series. However, an analysis of the patients taking part in the Mayo Clinic controlled trial of treatment for active chronic hepatitis showed that the only consistent difference to emerge was that these patients initially had more active disease than those in whom the test was negative. ${ }^{12}$ Their response to treatment was no different. In a further analysis of factors of possible prognostic importance Gitnick et al. ${ }^{13}$ found that the presence of lupus erythematosus cells (in 33\%), HBAg $(14 \%)$, and smooth muscle antibody $(86 \%)$ did not influence the prognosis, though this appeared to be worse in those patients with anticomplementary activity in their serum. Such anticomplementary activity (the ability of the serum to activate the complement system without added antigen) was detected while carrying out complement fixation tests for HBAg. Though it may indicate the presence of immune complexes, bacterial contamination of sera, other contaminants, or electrolyte abnormalities may have the same effect. Furthermore anticomplementary activity is not specific for a particular antigen-antibody system and so is not necessarily related to HBAg. Unfortunately, Gitnick and his colleagues did not carry out electronmicroscopic or further immunological studies to confirm that antigen-antibody complexes were present. Other workers, however, have described complexes containing HBAg on electron microscopy of sera from patients with antigenpositive active chronic hepatitis. ${ }^{14} 15$

Though there may be minor differences, most of the important clinical and pathological features of the disease are present in all the subgroups of active chronic hepatitis so far described, and it seems most likely that the chronic liver cell destruction is due to a common immunopathological process. The results of all the controlled trials which have been reported to date also show that the approach to treatment should be the same. Prednisone is effective both in controlling the activity of the disease and in reducing mortality. ${ }^{16-18}$ Treatment with azathioprine alone seems no better than placebo, but it is possible that its use in combination with prednisone may allow a lower dose of steroid to be used with a consequent reduction in steroid side effects. ${ }^{17}$

1 Doniach, D., Roitt, I. M., Walker, J. G., and Sherlock, S., Clinical and Experimental Immunology, 1966, 1, 237.

Miller, J., et al., Lancet, 1972, 2, 296

3 Golding, P. L., Smith, M. G. M., and Williams, R., American Fournal of Medicine, 1973, 55, 772 .

Medicine, 1973, 55, 772.
Galbraith, R. M., et al., New England Fournal of Medicine, 1974, $290,63$. 5 Galbraith, R. M., et al., New England fournal of Medicine

Reed, W. D., et al., Lancet, 1973, 2, 690 .

Bianchi, P., et al., Gastroenterology, 1972, 63, 482

Sherlock, S., Fox, R. A., Niazi, S. P., and Scheuer, P. J., Lancet, 1970, 1, 1243.

Bulkley, B. H., Heizer, W. D., Goldfinger, S. H., Isselbacher, K. J., and Shulman, N. R., Lancet, 1970, 2, 1323.

10 Cooksley, W. G. E., et al., Australian and New Zealand Fournal of Medicine, 1972, 2, 261.

11 Mackay, I. R., and Wood, I. J., Quarterly fournal of Medicine, 1962, 31, 485.

12 Soloway, R. D., Summerskill, W. H. J., Baggenstoss, A. H., and Schoenfield, L. J., Gastroenterology, 1972, 63, 458.

13 Gitnick, G. L., Summerskill, W. H. J., Soloway, R. D., Ritman, S., and Schoenfield, L. J., Archives of Internal Medicine, 1973, 213, 502.

${ }_{14}$ Almeida, June D., and Waterson, A. P., Lancet, 1969, 2, 983.

15 Reed, W. D., et al., Lancet, 1973, 2, 1347.

Cook, G. C., Mulligan, R., and Sherlock, S., Quarterly fournal of Medicine, $1971,40,159$.

17 Soloway, R. D., et al., Gastroenterology, 1972, 63, 820.

18 Murray-I yon, I. M., Stern, R. B., and Williams, R., Lancet, 1973, 1, 735

\section{Respiratory Complications of Obesity}

Overweight people often develop abnormalities in pulmonary function in the absence of primary lung disease, though they often develop chronic obstructive bronchitis too. The effects of obesity on pulmonary function vary widely in severity, and this does not necessarily depend on the degree of overweight. In most obese persons the pulmonary changes are trivial and are detectable only by pulmonary function measurements, but in others, especially those who develop hypoventilation, severe abnormalities may develop and death may occur from respiratory complications.

Oxygen consumption and carbon dioxide production are greater than normal in the obese both at rest and on exercise, ${ }^{1}$ implying that they have to ventilate more than usual to maintain normal arterial blood gas tensions. But the layers of fat on the chest wall and abdomen reduce the bellows action of the thoracic cage, the diaphragm is elevated, and the total work of breathing is increased, due mainly to reduced chest wall compliance. The functional residual capacity is low (because the expiratory reserve volume is much reduced) so that the resting end-expiratory position is lower than normal in the obese. This leads to low ventilation-perfusion ratios in the basal regions, more marked in the supine position. Nevertheless, in spite of the presence of hypoxaemia, most obese persons can maintain a normal level of alveolar ventilation and a normal arterial carbon dioxide tension. ${ }^{2}$

The association of obesity, episodic somnolence, hypoventilation, and cor pulmonale is often referred to as the Pickwickian syndrome, ${ }^{3}$ after the messenger Joe, "the fat and red-faced boy" described by Charles Dickins in The Pickwick Papers. This syndrome occurs in some $10 \%$ of obese subjects; in addition to hypoxaemia and abnormalities of thoracic mechanics there is alveolar hypoventilation and hypercapnia, and it is this finding that distinguishes the syndrome from the pulmonary consequences of simple obesity. The Pickwickian syndrome may occur in the non-obese, when it is usually associated with neurological abnormalities, ${ }^{4}$ but neurological disorders are not invariably present ${ }^{5}$ and in these circumstances the condition is usually called primary alveolar hypoventilation. 
It is not yet clear whether the Pickwickian syndrome is due solely to impaired pulmonary mechanics consequent on obesity or whether there is in addition decreased sensitivity of the respiratory centre to carbon dioxide. The ventilatory response to carbon dioxide is diminished when the mechanical work of breathing is increased, ${ }^{6}$ and the range of response to inhaled carbon dioxide in normals is wide; there are normal individuals who underventilate and retain carbon dioxide, despite normal body weight and lung mechanics, ${ }^{7}$ and it may be it is these people who develop the Pickwickian syndrome if they become obese. ${ }^{8}$ Paradoxically, in some obese subjects without hypoventilation the ventilatory response to inhaled carbon dioxide is normal or increased; it becomes less after loss of weight, due possibly to a reduction in the oxygen cost of breathing. ${ }^{9}$

The dangers of the Pickwickian syndrome are probably not sufficiently realized. Miller and Granada ${ }^{10}$ found that seven patients with gross obesity died in one hospital in New York during a five-year interval. Deaths were due to hypoventilation, pulmonary embolism, and acute renal failure, probably secondary to renal vein thrombosis. They emphasize the need for the early use of assisted ventilation, the vigorous treatment of congestive cardiac failure with digitalis, diuretics, and venesection, and they recommend that anticoagulants should be used in all such cases. They suggest further that obese patients with heart failure and venous stasis should be placed on anticoagulant therapy before hypoventilation developswhich seems wise advice and is already the practice of many physicians today.

1 Dempsey, J. A., et al., Fournal of Applied Physiology, 1966, 21, 1807. 2 Bates, D. V., Macklem, P. T., and Christie, R. V., Respiratory Function in Disease, 2nd edn., p. 100. London, W. B. Saunders and Co., 1971.

3 Burwell, C.. S., et al., The American fournal of Medicine, 1956, 21, 811

4 Rodman, T., et al., The American fournal of Medicine, 1962, 32, 208. Hargrave, S. A., Legge, J. S.,
Anaesthesia, 1973, 45, 111.

Anaesthesia, 1973, 45, 111.
Milic-Emili, J., and Tyler, J. M., Fournal of Applied Physiology, 1963, 18, 497.

7 Lambertsen, C. J., Anesthesiology, 1960, 21, 642.

8 MacGregor, M., Block, A. J., and Ball, W. C., Fohns Hopkins Medical fournal, 1970, 126, 279.

9 Emirgil, C., and Sobol, B. J., American Review of Respiratory Disease, 1973, 108, 831 .

${ }^{10}$ Miller, A., and Granada, M., The American fournal of Medicine, 1974, 56, 144.

\section{Stilboestrol for Prostatic Cancer}

No one with experience of the management of prostatic cancer would dispute the inestimable symptomatic benefit conferred by oestrogen therapy. Nevertheless, the precise mechanism of its action remains undecided, and controversy continues over case selection, timing, and dosage. Some practical help with these problems is given by a recent report ${ }^{1}$ from the Veterans Administration Cooperative Urological Research Group.

Hailed 35 years ago as a unique advance in the treatment of malignancy by the oral route, the effect of diethyl stilboestrol was regarded as primarily due to the neutralization or suppression of androgenic stimulation of cancers thought of as hormone-dependent. Though this concept of hormone sensitivity has been sustained in at least a majority of prostatic tumours further research has suggested that oestrogens may also act humorally or by local interference with the metabolism of the cancer cells.

Initial hopes that such treatment might in fact provide a cure for the disease led to its somewhat indiscriminate adop- tion as a possible panacea. Subsequent recognition of resistant or relapsing cases soon modified this suggestion, however, while the incidence of side effects and occasional intolerance emphasized the need for more cautious selection of cases in which the diagnosis had been fully confirmed. Though most of the therapeutic complications appeared trivial in comparison with the dangers of the disease the serious effect of water retention in patients with heart disease and the occasional occurrence of severe hepatic damage after intensive therapy imposed a further need for restraint. The earlier swing from minute "gynaecological" doses of stilboestrol to vastly greater quantities (varying from 100 to $1,000 \mathrm{mg}$ a day) in the hope of improving the response was thus halted, particularly as the prospect of inducing a permanent cure appeared to have receded. Further experience led to suggestions that some patients receiving oestrogens became unduly prone to thrombotic and cardiovascular complications. This view received considerable statistical support from a large collective series of cases investigated ${ }^{2}$ by the Veterans Administration which indicated that many patients receiving even moderate doses of stilboestrol in fact died from cardiovascular or thrombotic incidents rather than from cancer. Though the symptomatic benefits of treatment received but scant attention in that report it was clear that some reappraisal was called for and that the optimum dosage and timing of treatment should be reevaluated.

These points have now been clarified to some extent, and with improved means of staging the disease some measure of agreement has been reached. In general, so long as the disease remains confined to the primary site and is producing little in the way of symptoms oestrogen therapy is best deferred, and this applies particularly to local malignant nodules and to those often detected fortuitously on microscopy after prostatic surgery. In symptomatic cases alternative forms of treatment by palliative surgery, radiotherapy, or castration may also be considered, qualified by the age and condition of the patient and the availability of appropriate facilities. In cases with advanced local or metastatic spread there is, however, more general agreement that the symptomatic benefits of oestrogen therapy should not be withheld, and it is mainly the matter of dosage which remains in dispute.

The recent Veterans report, ${ }^{1}$ based on further clinical experience and the results of hormone assays, suggests that treatment with $1 \mathrm{mg}$ stilboestrol daily is effective in promoting both androgen suppression and symptomatic relief while reducing the risk of thrombosis. It is open to question, however, how far the results of the newly available methods of plasma androgen determination by radioimmunoassay can be taken as reflecting the response of the disease. Furthermore it has been shown from repeated hormone assays over a period of 24 hours that there is a considerable diurnal variation in the plasma testosterone and that doses of $1 \mathrm{mg}$ stilboestrol daily fail to achieve sustained suppression. ${ }^{3}$ It seems rational, therefore, either to increase the frequency of administration to $1 \mathrm{mg}$ t.d.s. or to rely on a somewhat higher once daily dosage of about $5 \mathrm{mg}$ to ensure a more uniform effect. Clinical considerations should always, however, remain paramount and, since the recent statistics ${ }^{1}$ point to an unexplained drop in the liability to thrombosis after a period of treatment it may perhaps be appropriate later to increase the dose if symptoms are inadequately controlled.

1 Byar, David, P., Cancer, 1973, 32, 1126. Surgery, Gynaecology and Obstetrics with International Abstracts of Surgery, 1967, 124, 1011.

shearer, R. J., Hendry, W. F., Sommerville, L. F. and Fergusson, J. D., British fournal of Urology, 1973, 45, 668. 